\title{
(2) OPEN ACCESS \\ Rapid arousal from anaesthesia after reversal of deep rocuronium-induced neuromuscular block with sugammadex in a neuroradiological procedure
}

\author{
Matteo Giuffrida 다, ${ }^{1}$ Nicola Susan Ledingham, ${ }^{1}$ Paolo Machi, ${ }^{2}$ \\ Christoph Andreas Czarnetzki ${ }^{1,3,4}$
}

${ }^{1}$ Division of Anaesthesiology, Department of Anaesthesiology, Intensive care and Emergency Medecine, Ente Ospedaliero Cantonale, Lugano, Switzerland ${ }^{2}$ Division of Neuroradiology, Geneva University Hospitals, Geneva, Switzerland ${ }^{3}$ Division of Anaesthesiology, Geneva University Hospitals, Geneva, Switzerland

${ }^{4}$ Faculty of Medecine, University of Geneva, Geneva, Switzerland

\section{Correspondence to}

Dr Christoph Andreas

Czarnetzki;

christoph.czarnetzki@eoc.ch

Accepted 8 August 2021

\section{SUMMARY}

We describe the case of a 42-year-old man undergoing elective embolisation of an arteriovenous malformation at the level of the right posterior cerebral artery under propofol anaesthesia. We used the SedLine Brain Function Monitor (Masimo) to titrate the anaesthetic depth with propofol. At the end of the procedure, the patient aroused from anaesthesia very rapidly after the reversal of deep neuromuscular block with sugammadex, despite still significant calculated doses of propofol at the effect site. This rapid arousal was monitored using the SedLine Brain Function Monitor.

\section{BACKGROUND}

Monitoring of anaesthetic depth during the surgery and other interventions, such as neuroradiological procedures allows adapting anaesthetic doses, in order to maintain haemodynamic stability, decrease anaesthetic related morbidity such as cognitive dysfunction and to target rapid awakening in often fragile and polymorbid patients. ${ }^{12}$ A further important aim of monitoring depth of anaesthesia is to avoid awareness. The majority of cases of awareness during general anaesthesia occur when neuromuscular blocking agents are used (1: 8200 with neuromuscular blocking agents vs 1: 135900 without). ${ }^{3}$

\section{CASE PRESENTATION}

We describe the case of a 42 -year-old man $(75 \mathrm{~kg}$, $177 \mathrm{~cm})$, American Society of Anesthesiologists (ASA) II for smoking (20 pack-years) as the only history. He presented to the emergency department due to headache and one episode of vomiting. Headache initially was relieved by simple analgesia which subsequently became resistant to therapy. CT angiography demonstrated right intraventricular haemorrhage without a clear source of bleeding. MRI found a stable right thalamic haematoma probably originating from a leaking arterial-venous malformation. A cerebral arteriography performed the next day concluded that the haematoma probably originated from a branch of the right posterior cerebral artery. The neurologically asymptomatic patient was scheduled for an elective embolisation of the arterial-venous malformation under general anaesthesia 1 week later. The patient was fasted for at least 6 hours before anaesthesia and received no premedication. Standard monitoring included a

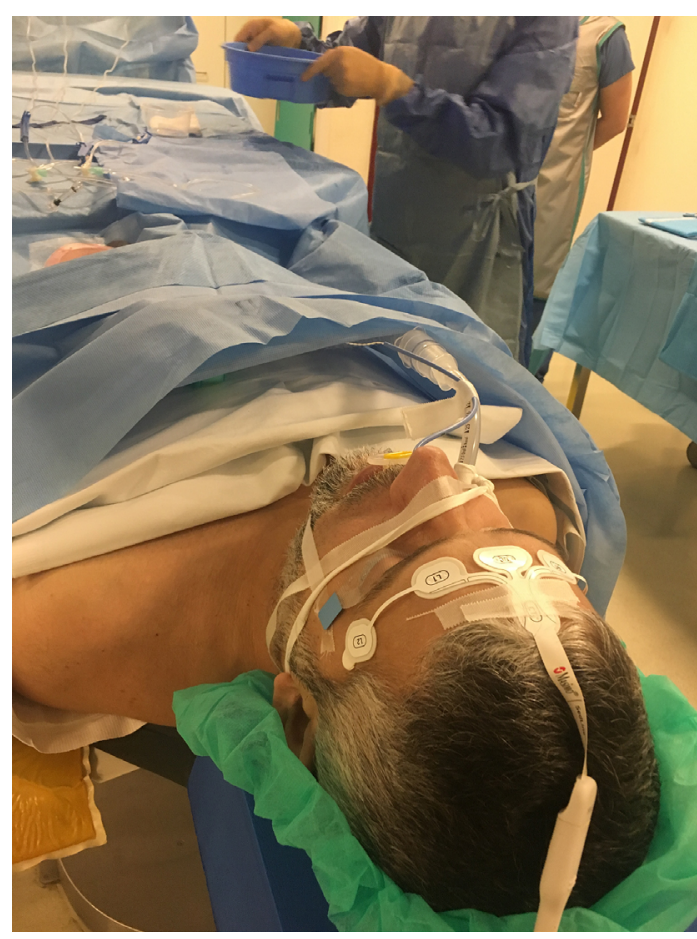

Figure 1 The RD SedLine EEG Sensor installed on the patient's forehead. EEG, electroencephalogram.

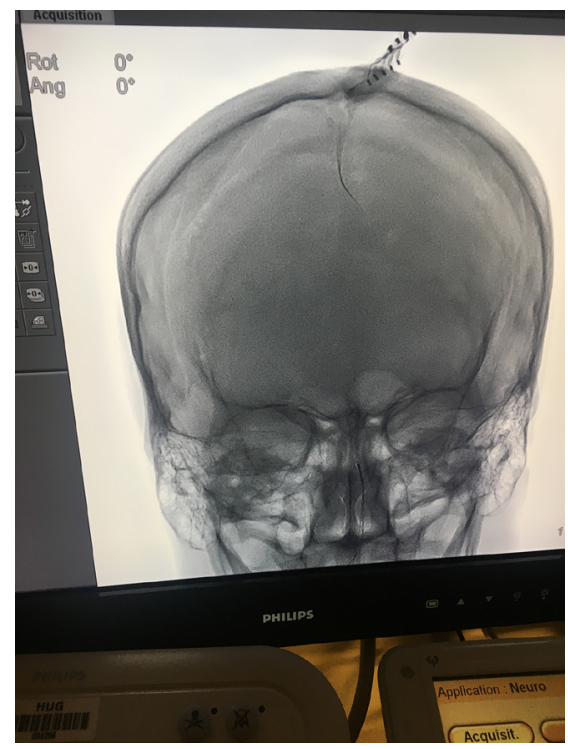

Figure 2 The RD SedLine EEG sensor not visible on the anterior-posterior X-ray of the skull. EEG, electroencephalogram. 


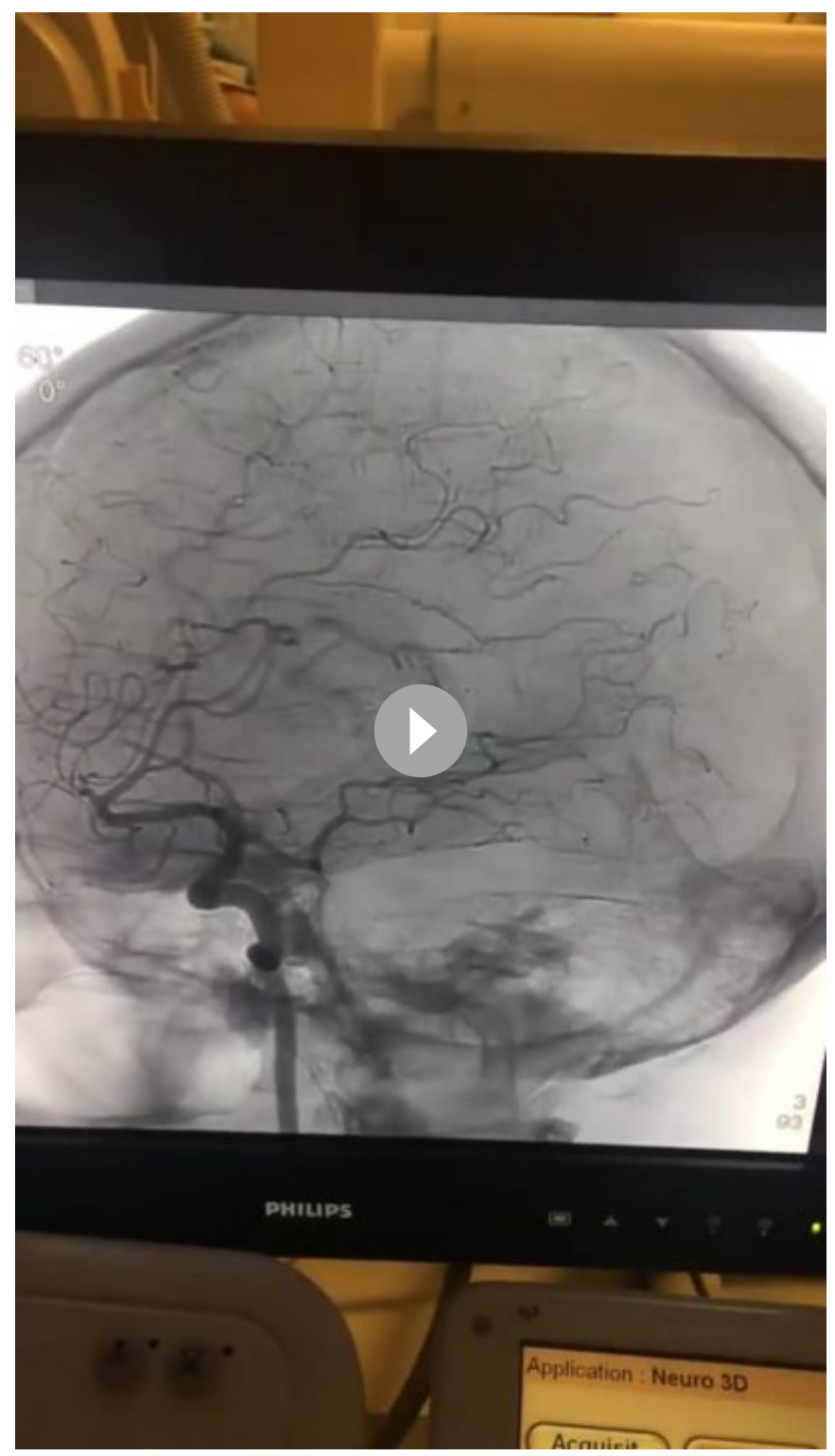

Video $1360^{\circ}$ image of the skull with no visible electrodes.

three-lead ECG, non-invasive blood pressure, end-tidal partial pressure of carbon dioxide and peripheral pulse oximetry. To monitor the depth of anaesthesia, we used the SedLine Brain Function Monitor (Masimo). The bilateral SedLine electroencephalogram (EEG) Sensor was installed on the patient's front (figure 1). The front electrodes were not visible on the operator's X-ray screen (figure 2, video 1) and did not disturb at any moment the operator during the procedure. The cable of the sensor was conducted posteriorly with respect to the patient's head and kept out the field of the radiological image (figure 3). Anaesthesia was induced and maintained with a target-controlled infusion (TCI) of propofol (Orchestra Base Primea, Fresenius Kabi) using the pharmacokinetic model of Schnider $e^{2}$ al $^{4}$ Analgesia was assured with intermittent boluses of sufentanil $0.2 \mu \mathrm{g} / \mathrm{kg}$. The lungs were normoventilated (endtidal partial pressure of carbon dioxide, $4.6-6.0 \mathrm{kPa}$ ) with $50 \%$ oxygen-air mixture. Neuromuscular block was induced with rocuronium bromide $0.6 \mathrm{mg} / \mathrm{kg}$ and maintained with intermittent boluses of $0.2-0.3 \mathrm{mg} / \mathrm{kg}$ to obtain a deep neuromuscular block (post tetanic count of 2) measured with acceleromyography on the patients left thumb (IntelliVue NMT Module,

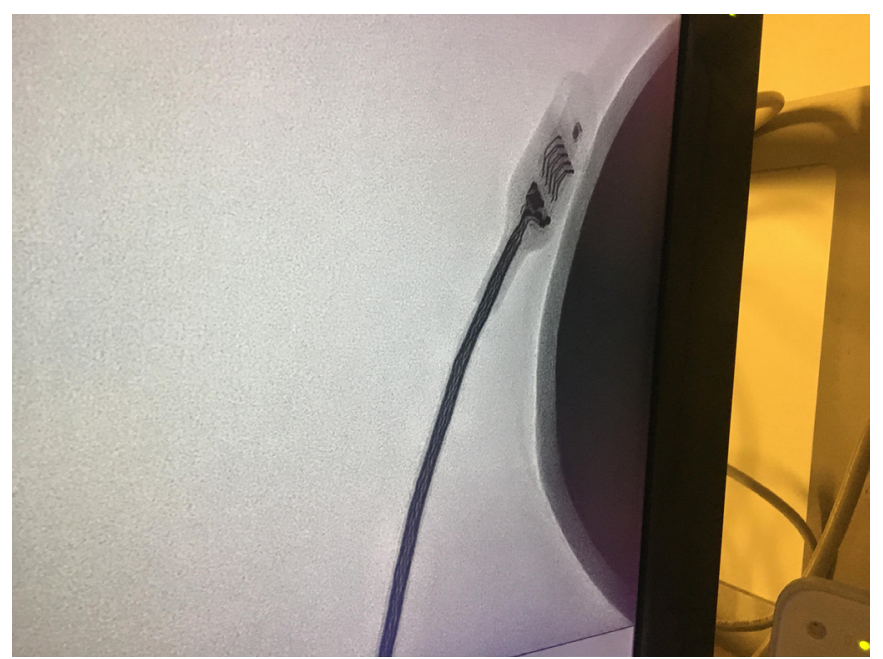

Figure 3 The RD SedLine EEG sensor cable on the lateral X-ray. EEG, electroencephalogram.

Philips). After intubation an invasive arterial line was placed in the right radial artery. We used the Patient State Index (PSI) of the SedLine Brain Function Monitor to titrate the depth of anaesthesia targeting a PSI between 25 and 50..$^{5}$ Relatively low calculated doses of propofol were necessary to maintain a stable depth of anaesthesia, with calculated effect-site concentrations of about $2.6 \mu \mathrm{g} / \mathrm{mL}$ (figure 4) and a PSI of about 27 (figure 5). The neuroradiological intervention was uneventful but was ended after 2 hours without embolisation of the arteriovenous malformation as no source vessel could be identified. The target-controlled perfusion of propofol was stopped (local time 13:30, total perfusion time 2 hours and $18 \mathrm{~min}$, total propofol dose $1043 \mathrm{mg}$ ) and $2 \mathrm{~min}$ later (local time 13:32) the patient received sugammadex intravenously $(4 \mathrm{mg} / \mathrm{kg})$ to reverse deep neuromuscular block with a train of four count of 0 (post-tetanic

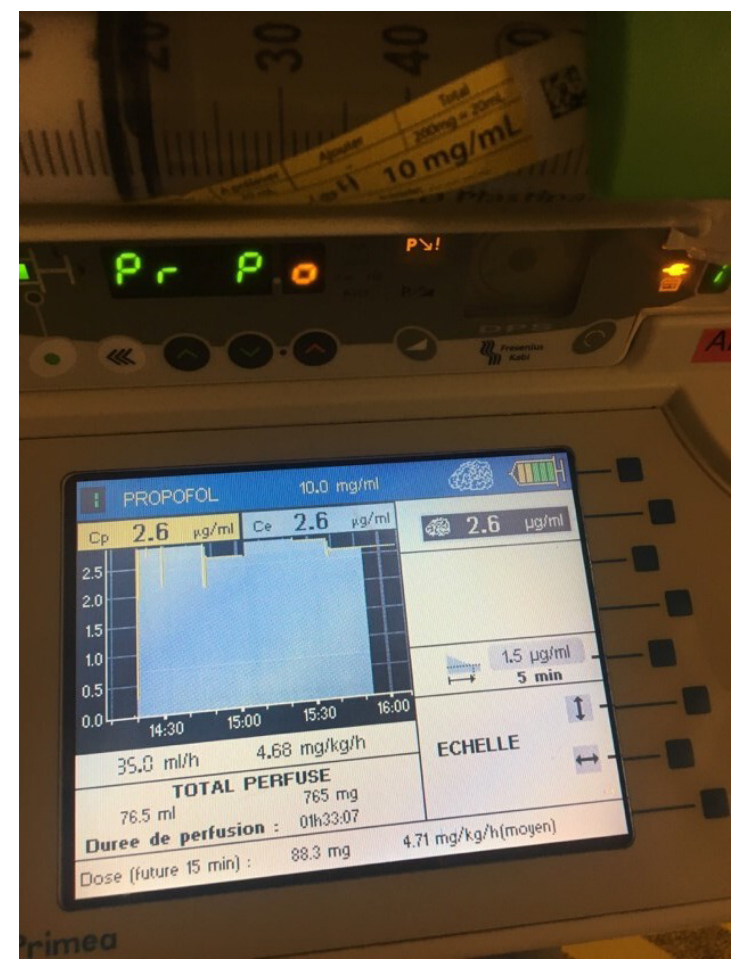

Figure 4 Target-controlled infusion of propofol during anaesthesia. 


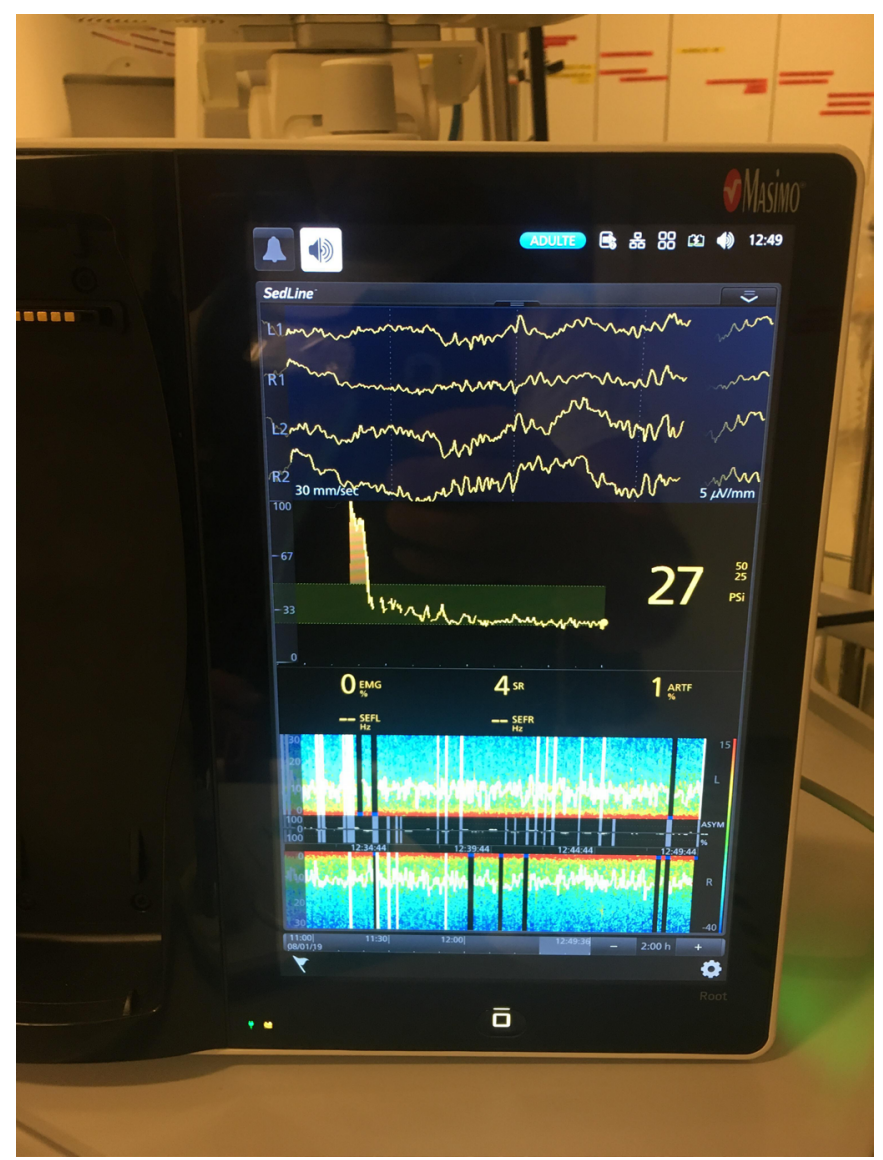

Figure 5 PSI value during anaesthesia. PSI, Patient State Index.

count was not done before reversal). Very rapidly thereafter without any stimulation the patient aroused from anaesthesia (local time 13:33) (video 2). The patient was extubated $4 \mathrm{~min}$ after the injection of sugammadex with a propofol effect site concentration of $2.0 \mu \mathrm{g} / \mathrm{mL}$ (figure 6) and a train of four ratio of $100 \%$. After extubation $(13: 37)$ the patient displayed eye opening but had difficulty responding to questions (video 3). During stable anaesthesia, the raw EEG showed a very slow and depressed brain activity with zero EMG activity and spectral edge frequencies (the frequency below which 95 precent of the total electroencephalogram power is located) of around $10 \mathrm{~Hz}$ for both hemispheres and a PSI around 27. The event of immediate arousal from anaesthesia was followed by a very steep increase in the PSI index (up to 80 and more) with an EMG activity of $80 \%$ and a spectral edge frequency of about $17 \mathrm{~Hz}$ (figure 7). Spectrogram analysis showed a monotonous content in the delta range in the first part followed by a complex and increasing electrical brain activity. The white bars indicate background artefacts due to movement.

\section{OUTCOME AND FOLLOW-UP}

The patient was transferred to the intermediate neurological care unit for 2 days and thereafter to the neurology ward. After 6 days of an uneventful hospital stay, he returned home without any neurological deficit. Five months later, the arteriovenous malformation was treated successfully with Gamma Knife radiosurgery. The patient received regular postoperative follow-up which was uneventful.

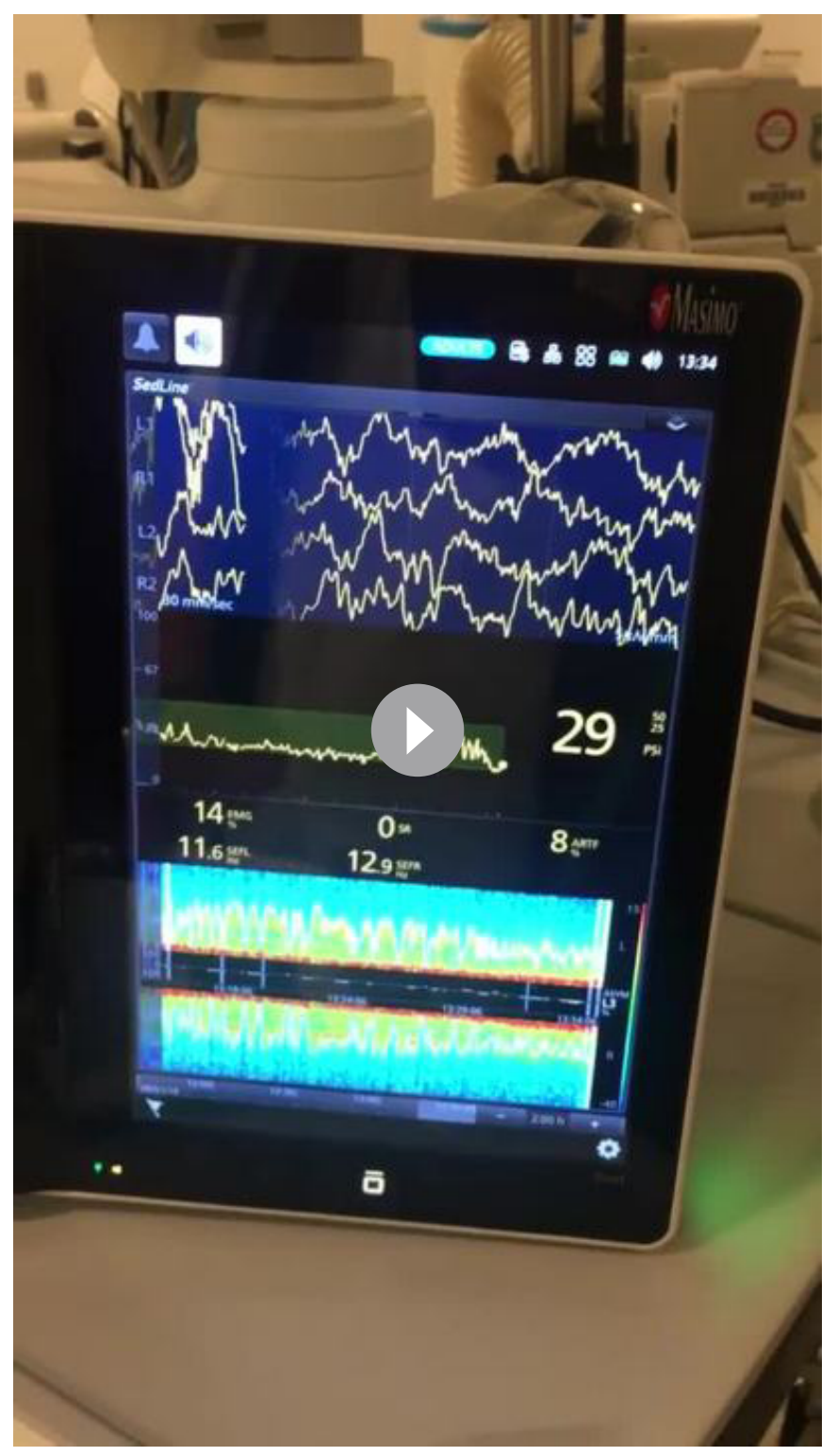

Video 2 Immediate arousal after sugammadex.

\section{DISCUSSION}

In this case report, we describe a case of rapid arousal form anaesthesia after the reversal of deep rocuronium-induced neuromuscular block with sugammadex despite still significant calculated doses of propofol at the effect site. Signs of light anaesthesia have been reported after sugammadex administration in several dose-finding studies. ${ }^{67}$ Chazot et al reported a case who immediately awoke after sugammadex administration in absence of any stimulation with still adequate anaesthesia under propofol and remifentanil. ${ }^{8}$ In this patient brain function monitoring was done with Bispectral Index (BIS) (BIS; Aspect Medical System, Norwood, Massachusetts, USA) and Neurosense (Neurowave System, Cleveland, Ohio, USA). In 2020, a randomised clinical trial by Le Guen et al in 51 patients showed that despite constant perfusion with propofol and remifentanil, sugammadex causes signs of awakening in the absence of documented post-operative awareness. ${ }^{9}$ The BIS monitor was used to monitor anaesthetic depth. Sugammadex is reported in the literature to have a very low affinity for other molecules such as propofol. ${ }^{78}$ Consequently its direct interference with the depth of anaesthesia (in terms of displacement of the hypnotic agent) is considered to 


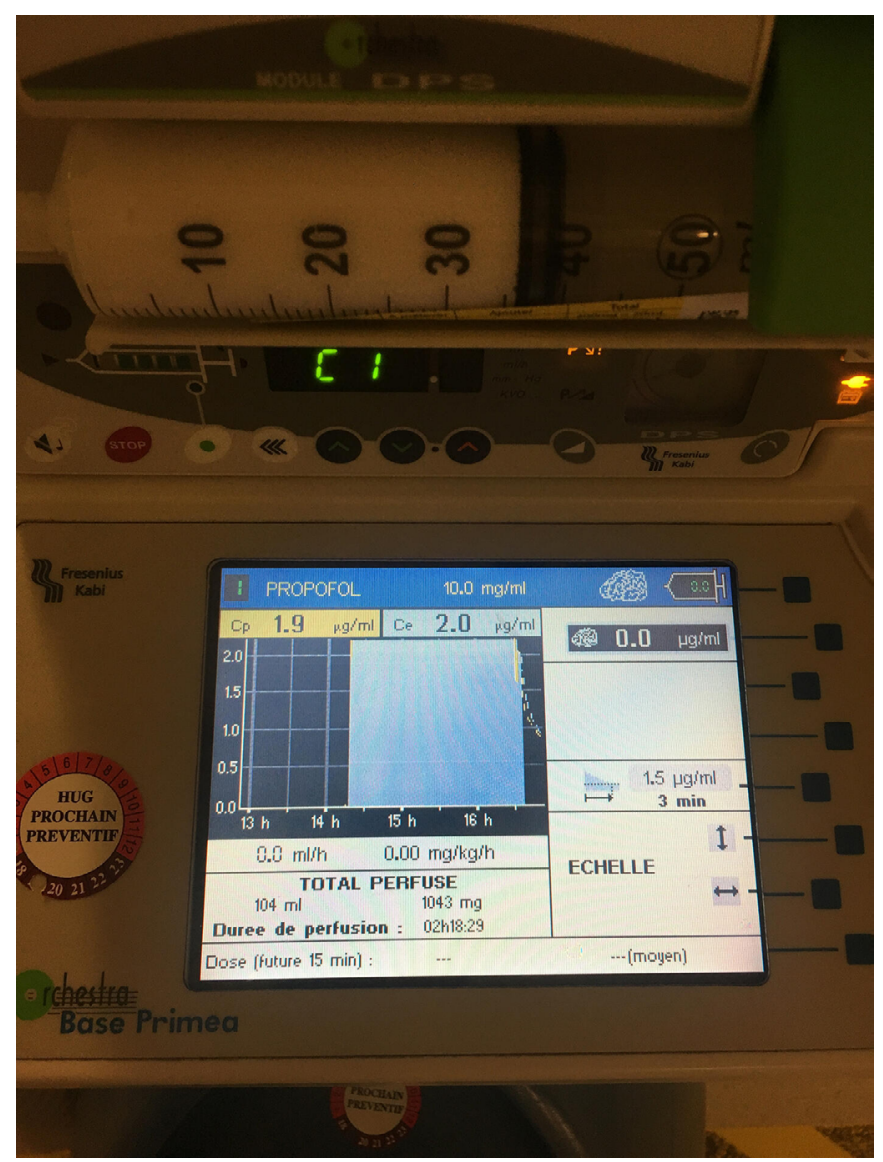

Figure 6 Propofol effect site concentration and total dose at arousal.

be clinically irrelevant. The case presented here differs from the previous ones in that the Sedline Brain function Monitor Masimo was used. This monitor produces a parameter called PSI derived from a proprietary algorithm by processing a high-resolution four-channel EEG with advanced artefact filters. ${ }^{10}$ The PSI has been clinically validated to measure the depth of anaesthesia and sedation. ${ }^{11} 12$ The calculation of the PSI takes about 2 min. It uses parallel signal processing engines to extract a clearer EEG signal for computing PSI. It is thus less influenced by artefacts arising from neuromuscular blockade which limit other monitoring techniques as previously demonstrated by Schuller et al. ${ }^{13}$ In particular, the BIS has been shown to be highly influenced by peripheral electromyography which contributes considerably to the diagnosis of high BIS, and is particularly essential for determining BIS $>80 .{ }^{14}$ The bilateral Masimo Sedline electrodes are radiolucent and were not disturbing during the neuroradiological procedure. The patient underwent 2 hours of general anaesthesia using a Propofol TCI according to the pharmacokinetic model of Schnider et $\mathrm{al}^{4}{ }^{4}$ with a calculated effect site concentration of about $2.6 \mu \mathrm{g} / \mathrm{mL}$. The patient was kept under deep neuromuscular block (post-tetanic count 2) due to the inherent safety requirements of the neuroradiological intervention. The lecture of the PSI, the interpretation of the bilateral raw EEG and the density spectral array (DSA), allowed us to titrate the anaesthetic drugs to the minimum dosages for effective and safe hypnosis. Intracerebral pathologies might give asymmetric BIS values, but the thresholds at which the extent and type of intracranial pathologies affect BIS are largely unknown. ${ }^{15}$ This should be kept in mind using brain function monitoring in neuroradiological interventions. Our patient had a normal neurological examination before the procedure and the intracerebral

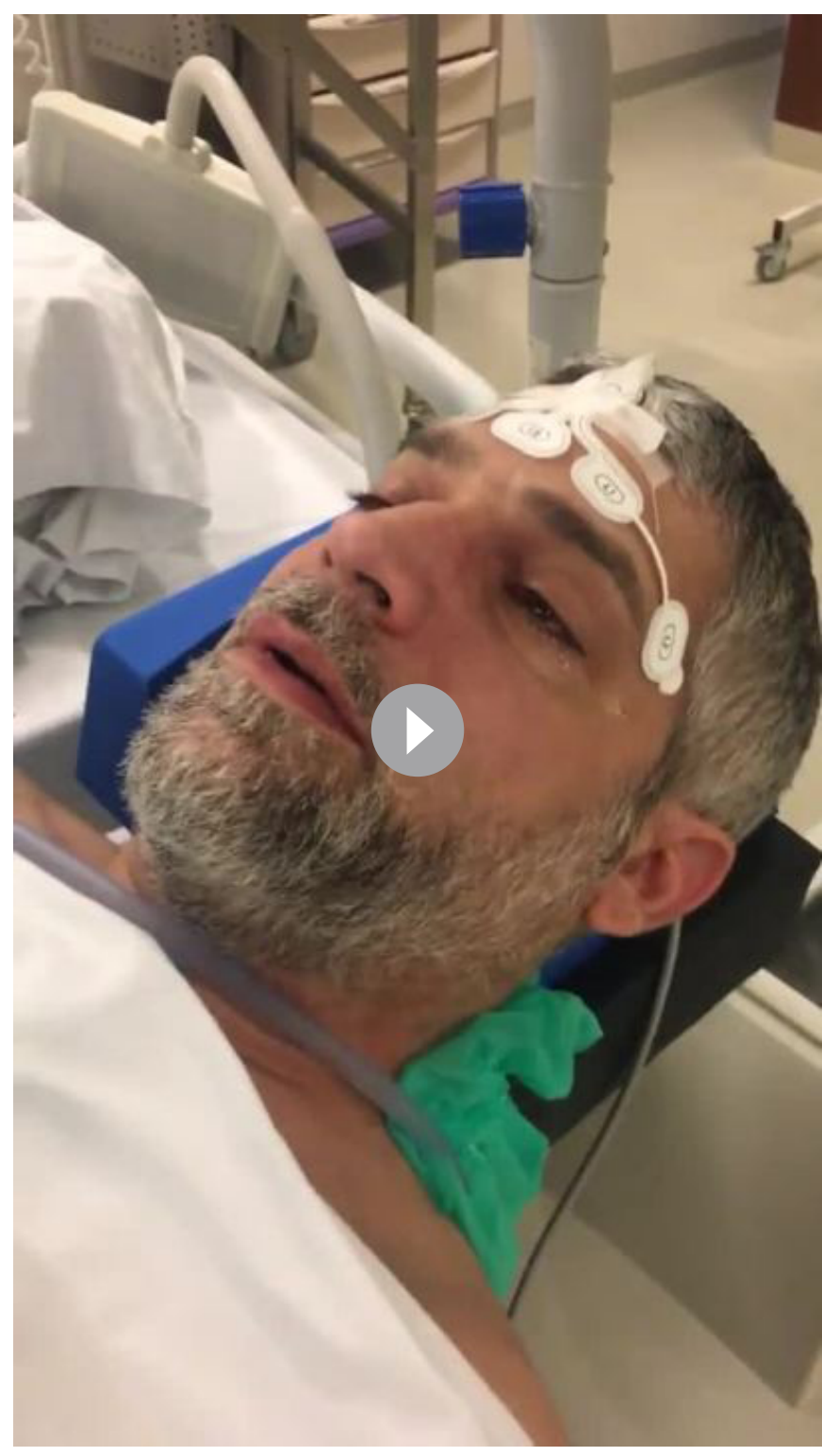

Video 3 Patient awake.

bleeding had happened 1 week before the intervention. There was no asymmetry in the DSA. We might, therefore, believe that the calculated PSI correctly reflected anaesthetic depth in this patient. At the end of the procedure, only 2 min after having stopped the propofol perfusion the patient emerged very rapidly and unexpectedly after the administration of sugammadex at a dose of $4 \mathrm{mg} / \mathrm{kg}$. This immediate awakening was documented by Masimo Sedline monitoring. Postmedication excluded signs and symptoms suggestive of awareness. TCI are used routinely to simplify the administration of intravenous drugs during general anaesthesia and to increase its precision but there are large variations in measured serum concentrations. ${ }^{17}$ One might argue that anaesthetic depth of the patient was already very superficial at the moment we stopped the propofol perfusion, and that the indicated effect site concentrations are calculated and not measured values, but this would have been reflected in a higher PSI value which was about 27 at this moment and which indicated adequate anaesthesia. It is very improbably that the $2 \mathrm{~min}$ interruption of the propofol perfusion induced this very rapid arousal (about $2 \%$ of total propofol perfusion time). We believe that the observed effect of sugammadex is indirect and might 


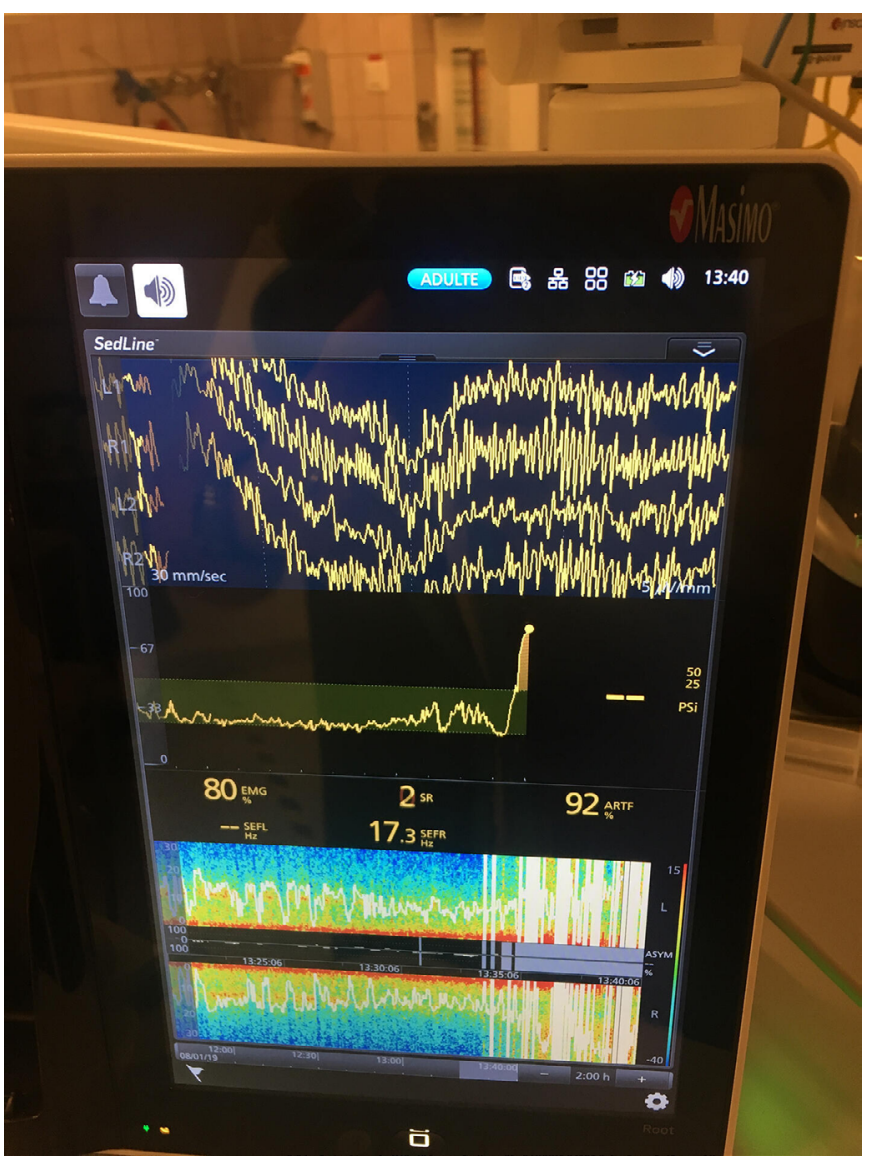

Figure 7 Steep rise of PSI at arousal. PSI, Patient State Index.

be mainly explained by the afferentation theory. The latter was first described by Lanier et al on a sample of $\operatorname{dogs}^{18}$ and later taken up by Vasella et al. ${ }^{19}$ The afferentation theory predicts that stimulation of the neuromuscular spindles will produce cerebral stimulation. Cortical activity has therefore a peripheral component deriving from muscular proprioceptive afferences. Neuromuscular block would lead to a 'peripheral silence' which sugammadex could interrupt. Compared with previous reports,

\section{Patient's perspective}

Here there are some words about my experience under general anaesthesia: 'I fell asleep very easily, without stress, but I was scared of awakening with nausea. When I woke up, it was as if nothing had happened. I woke up very well. I also vividly remember well what we had talked about just before I fell asleep and especially an awakening without nausea and without having the "head among the clouds' (Translated from French)

\section{Learning points}

Reversal of rocuronium induced neuromuscular block with Sugammadex may induce rapid arousal from anaesthesia.

- This rapid arousal might be explained by the afferentation theory.

- Brain function monitoring to avoid awareness and titrate depth of anaesthesia could be of utmost importance in patients receiving neuromuscular blocking agents. we used a neuromonitoring method that does not depend on peripheral electromyography, which, therefore, allows us to study more precisely the changes in cortical activity which were observed after the administration of Sugammadex.

In conclusion, this case illustrates the possibility of unexpectedly rapid emergence from effect site-targeted propofol anaesthesia on reversal of neuromuscular blockade with sugammadex. A potential explanation behind this phenomenon could be the sugammadex-induced indirect increase of central stimulation via the reactivation of ascending central pathways originating from neuromuscular spindles. These observations argue for the need of further research between the interaction of neuromuscular blockade and depth of anaesthesia.

\section{Twitter Christoph Andreas Czarnetzki @czarchris}

Contributors MG: This author helped with the study concept and design of the work, drafted the work, gave approval of the version published, gave his agreement to be accountable for all aspects of the work in ensuring that questions related to the accuracy or integrity of any part of the work are appropriately investigated and resolved. NSL: This author helped with the study concept and design of the work, revised it critically for important intellectual content, gave approval of the version published, gave his agreement to be accountable for all aspects of the work in ensuring that questions related to the accuracy or integrity of any part of the work are appropriately investigated and resolved. PM: This author helped with the study concept and design of the work, revised it critically for important intellectual content, gave approval of the version published, gave his agreement to be accountable for all aspects of the work in ensuring that questions related to the accuracy or integrity of any part of the work are appropriately investigated and resolved. CAC: This author helped with the study concept and design of the work, revised it critically for important intellectual content, gave approval of the version published, gave his agreement to be accountable for all aspects of the work in ensuring that questions related to the accuracy or integrity of any part of the work are appropriately investigated and resolved

Funding The authors have not declared a specific grant for this research from any funding agency in the public, commercial or not-for-profit sectors.

\section{Competing interests None declared.}

\section{Patient consent for publication Obtained.}

Provenance and peer review Not commissioned; externally peer reviewed

Open access This is an open access article distributed in accordance with the Creative Commons Attribution Non Commercial (CC BY-NC 4.0) license, which permits others to distribute, remix, adapt, build upon this work non-commercially, and license their derivative works on different terms, provided the original work is properly cited and the use is non-commercial. See: http://creativecommons.org/ licenses/by-nc/4.0/.

\section{ORCID iD}

Matteo Giuffrida http://orcid.org/0000-0003-2774-7588

\section{REFERENCES}

1 Jung YS, Han Y-R, Choi E-S, et al. The optimal anesthetic depth for interventional neuroradiology: comparisons between light anesthesia and deep anesthesia. Korean J Anesthesiol 2015;68:148-52.

2 Shepherd J, Jones J, Frampton G, et al. Clinical effectiveness and cost-effectiveness of depth of anaesthesia monitoring (E-Entropy, bispectral index and Narcotrend): a systematic review and economic evaluation. Health Technol Assess 2013;17:1-264.

3 Pandit JJ, Andrade J, Bogod DG, et al. 5th national audit project (NAP5) on accidental awareness during general anaesthesia: summary of main findings and risk factors. $\mathrm{Br} J$ Anaesth 2014;113:549-59.

4 Schnider TW, Minto CF, Gambus PL, et al. The influence of method of administration and covariates on the pharmacokinetics of propofol in adult volunteers. Anesthesiology 1998;88:1170-82.

5 Drover DR, Lemmens HJ, Pierce ET, et al. Patient state index: titration of delivery and recovery from propofol, alfentanil, and nitrous oxide anesthesia. Anesthesiology 2002;97:82-9.

6 de Boer HD, Driessen JJ, Marcus MAE, et al. Reversal of rocuronium-induced (1.2 mg/ $\mathrm{kg}$ ) profound neuromuscular block by sugammadex: a multicenter, dose-finding and safety study. Anesthesiology 2007;107:239-44.

7 Sparr HJ, Vermeyen KM, Beaufort AM, et al. Early reversal of profound rocuroniuminduced neuromuscular blockade by sugammadex in a randomized multicenter study: efficacy, safety, and pharmacokinetics. Anesthesiology 2007;106:935-43. 
8 Chazot T, Dumont G, Le Guen M, et al. Sugammadex administration results in arousal from intravenous anaesthesia: a clinical and electroencephalographic observation. $\mathrm{Br} J$ Anaesth 2011;106:914-6.

9 Le Guen M, Roussel C, Chazot T, et al. Reversal of neuromuscular blockade with sugammadex during continuous administration of anaesthetic agents: a doubleblind randomised crossover study using the bispectral index. Anaesthesia 2020;75:583-90.

10 Drover D, Ortega H.R. (Rick), Ortega HRR. Patient state index. Best Pract Res Clin Anaesthesiol 2006;20:121-8.

11 Chen X, Tang J, White PF, et al. A comparison of patient state index and bispectral index values during the perioperative period. Anesth Analg 2002;95:1669-74.

12 Pichep LS, John ER, Gugino LD. Quantitative EEG assessment of changes in the level of Sedation/Hypnosis during surgery under general anaesthesia. Memory and Awareness in Anaesthesia 2000:97-107.

13 Schuller PJ, Newell S, Strickland PA, et al. Response of bispectral index to neuromuscular block in awake volunteers. Br J Anaesth 2015;115:195-103.
14 Hayashi K, Sawa T. The fundamental contribution of the electromyogram to a high bispectral index: a postoperative observational study. J Clin Monit Comput 2019;33:1097-103.

15 Sahinovic MM, Beese U, Heeremans EH, et al. Bispectral index values and propofol concentrations at loss and return of consciousness in patients with frontal brain tumours and control patients. Br J Anaesth 2014:112:110-7.

$16 \mathrm{Jo} \mathrm{KW,} \mathrm{Kim} \mathrm{T.} \mathrm{Asymmetric} \mathrm{bispectral} \mathrm{index} \mathrm{values} \mathrm{in} \mathrm{a} \mathrm{patient} \mathrm{with} \mathrm{traumatic} \mathrm{brain}$ injury. J Neurosurg Anesthesiol 2011;23:378.

17 Hoymork SC, Raeder J, Grimsmo B, et al. Bispectral index, serum drug concentrations and emergence associated with individually adjusted target-controlled infusions of remifentanil and propofol for laparoscopic surgery. Br J Anaesth 2003;91:773-80.

18 Lanier WL, laizzo PA, Milde JH, et al. The cerebral and systemic effects of movement in response to a noxious stimulus in lightly anesthetized dogs. Possible modulation of cerebral function by muscle afferents. Anesthesiology 1994;80:392-401.

19 Vasella FC, Frascarolo P, Spahn DR, et al. Antagonism of neuromuscular blockade but not muscle relaxation affects depth of anaesthesia. Br J Anaesth 2005;94:742-7.

Copyright 2021 BMJ Publishing Group. All rights reserved. For permission to reuse any of this content visit https://www.bmj.com/company/products-services/rights-and-licensing/permissions/

BMJ Case Report Fellows may re-use this article for personal use and teaching without any further permission.

Become a Fellow of BMJ Case Reports today and you can:

- Submit as many cases as you like

- Enjoy fast sympathetic peer review and rapid publication of accepted articles

- Access all the published articles

- Re-use any of the published material for personal use and teaching without further permission

\section{Customer Service}

If you have any further queries about your subscription, please contact our customer services team on +44 (0) 2071111105 or via email at support@bmj.com.

Visit casereports.bmj.com for more articles like this and to become a Fellow 